\title{
SISTEM INFORMASI PENJUALAN PADA TOKO JILBAB RJS KABUPATEN SUMBAWA BERBASIS WEB
}

\author{
Eri Sasmita Susanto ${ }^{1)}$, Yana Karisma ${ }^{2}$,Susi Isnaeni ${ }^{3)}$ \\ ${ }^{1)}$ Dosen Informatika Universitas Teknologi Sumbawa \\ ${ }^{2}$ Dosen Informatika Universitas Teknologi Sumbawa \\ ${ }^{3)}$ Mahasiswa Informatika Universitas Teknologi Sumbawa \\ eri.sasmita.susanto@uts.ac.id ${ }^{1)}$, yana.karisma@uts.ac.id ${ }^{2)}, \underline{\text { Uchyisnaeni98@gmail.com }}^{3)}$
}

\begin{abstract}
Abstrak
Toko jilbab RJS Kabupaten Sumbawa yang bergerak dalam bidang penjualan jilbab dan busana muslim mempunyai cukup banyak pelanggan dikarenakan harga dari produk yang dijual cukup variatif, maka dari itu dibutuhkan sebuah sistem informasi penjualan untuk membantu pelanggan membeli dan menerima informasi produk dari toko tersebut. Sistem informasi penjualan berbasis web ini bertujuan untuk membantu pelanggan atau konsumen toko jilbab RJS dapat melakukan pembelian dan mengetahui informasi produk secara online tanpa harus mendatangi toko secara langsung.

Penelitian ini bertujuan untuk membangun sebuah sistem informasi penjualan pada Toko Jilbab RJS Kabupaten Sumbawa berbasis web. Sistem ini dikembangkan menggunakan bahasa pemrograman PHP dengan menggunakan MySQL sebagai database. Metode Pengembangan Perangkat Lunak menggunakan Metode Waterfall. Pengujian perangkat lunak dilakukan melalui pengujian black-box, teknik pengumpulan data pada penelitian ini menggunakan observasi, wawancara, dokumentasi dan studi pustaka.

Hasil akhir yang di peroleh adalah sebuah sistem informasi penjualan berbasis web yang digunakan oleh toko jilbab RJS Kabupaten Sumbawa. Sistem ini mampu memberikan promosi produk, penjualan produk dengan pembayaran melalui rekening.
\end{abstract}

Kata Kunci: UTS, Sistem Informasi, Penjualan, Waterfall

\begin{abstract}
Hijab Shop RJS Sumbawa District that is engaged in the sale of hijab and Muslim fashion has enough customers because the price of the product sold is quite varied, hence it takes a sales information system to help Customers purchase and receive product information from the store. This web-based sales information system aims to help customers or consumers of RJS hijab shop can make purchases and know product information online without having to go to the store directly.

The research aims to build a sales information system on the RJS Hijab shop based on the web. The system was developed using the PHP programming language using MYSQL as a database. The software development method uses the Waterfall method. Software testing conducted through black-box testing, the data collection techniques on the study using observations, interviews, documentation and library studies.

The final result is a Web-based sales information system used by RJS Hijab shop in Sumbawa district. This system is able to provide product promotion, product sales with bank payments.
\end{abstract}

Keywords: UTS, Information Systems, Sales, Waterfall

\section{PENDAHULUAN}

\section{Latar Belakang}

Toko jilbab Rumah Jilbab Sumbawa (RJS) yang beralamat di Jalan Mawar No 36, Bugis, Kecamatan Sumbawa, Kabupaten Sumbawa merupakan sebuah badan usaha yang bergerak dalam bidang penjualan jilbab dan busana muslim. Selama ini pada toko jilbab RJS Sumbawa proses penjualannya masih menggunakan media tatap muka yaitu kegiatan penjualan dengan pembeli dilakukan dengan cara pembeli datang langsung pada toko jilbab RJS Sumbawa dikarenakan belum adanya pemanfaatan website atau sistem yang berbasis E-commerce. Demikian juga bisnis Toko jilbab RJS Sumbawa sebagai distributor outlet fashion harus memiliki manajemen dan strategi pemasaran sebagai usaha bersaing dari banyaknya kompetitor produk jilbab atau busana muslim lainnya yang ada di Sumbawa. Sebagai distributor 
atau agen jilbab dan busana muslim. Toko jilbab RJS Sumbawa harus melayani dan menyalurkan barang-barang ke beberapa tempat pemasaran pada wilayah Sumbawa.

Oleh karena itu dibutuhkan media yang bisa digunakan sebagai sarana bertransaksi bagi distributor dan agen kecil maupun konsumen pada umumnya.Sebagai bentuk layanan peningkatan mutu terhadap konsumen toko jilbab RJS Sumbawa membutuhkan sebuah sistem penjualan yang praktis dan cepat dari sistem penjualan yang ada. Untuk mengatasi masalah tersebut penulis membuat sistem penjualan menggunakan perangkat website agar proses penjualan dapat berjalan dengan cepat.

Dengan sistem ini, pelanggan toko jilbab RJS Sumbawa dapat langsung melakukan transaksi pembelian dan juga pelanggan dapat mengetahui harga barang, jenis serta model tanpa harus datang langsung ke toko. Adapun alasan penulis mengapa memilih toko jilbab RJS Sumbawa sebagai tempat melakukan penelitian yaitu karena harga dari barang atau produk pada toko jilbab RJS Sumbawa yang kompetitif sehingga penulis rasa kedepannya toko ini memiliki prospek yang sangat baik untuk berkembang. Maka dari itu penulis berharap dengan memanfaatkan media penjualan berbasis web dapat menguntungkan toko jilbab RJS Sumbawa dalam melakukan proses penjualan yang lebih efektif.

\section{Tujuan Penelitian}

Adapun tujuan dari penelitian ini yaitu untuk menghasilkan sistem informasi penjualan pada toko jilbab RJS Sumbawa agar proses penjualan dapat lebih efisien, akuntabel atau dapat dipercaya.

\section{Batasan Masalah}

Adapun batasan penelitian ini yaitu:

1. Penelitian ini dilakukan pada toko jilbab RJS Sumbawa.

2. Sistem informasi penjualan dalam web hanya menjual jilbab dan busana muslim.

3. Pada web tersebut konsumen dapat melakukan proses pembelian produk.

4. Proses pengiriman atau pengantaran barang hanya pada wilayah kota Sumbawa.

5. Bahasa pemrograman yang digunakan yaitu PHP.

6. Database yang digunakan yaitu MySQL.

\section{TINJAUAN PUSTAKA}

Rancang bangun sistem informasi terkait penjualan produk telah banyak dilakukan, yakni penelitian ${ }^{[1]}$ Prasetyo (2015) yang berjudul "Perancangan Sistem Penjualan Berbasis Aplikasi
Desktop Pada CV. Canangsari Semarang”. Dimana pada penelitian tersebut Prasetyo (2015) membuat perancangan sistem informasi penjualan pada $\mathrm{CV}$. Canangsari Semarang dengan tujuan dapat memudahkan petugas atau pengelola $\mathrm{CV}$. Canangsari Semarang dalam pengolahan dan penyajian data buku. Terdapat persamaan dari penelitian yang dilakukan oleh Prasetyo (2015) dengan penelitian yang penulis lakukan yaitu sama-sama membangun sistem informasi penjualan yang bermaksud mengubah sistem manual yang sedang berjalan dengan sistem yang terkomputerisasi. Namun terdapat juga perbedaannya, antara lain yaitu dalam penelitian Prasetyo (2015) membuat sistem informasi yang hanya dapat diakses oleh petugas atau pengelola CV. Canangsari Semarang serta tidak membahas proses pembayaran maupun pemesanan produk secara online. Sedangkan penulis membuat sistem informasi yang dapat diakses oleh petugas atau pengelola toko RJS Sumbawa dan masyarakat luas atau konsumen pada umumnya serta konsumen dapat melakukan proses pemesanan atau pembayaran secara online. Maka dengan hal itu dapat dilihat keunggulan dalam penelitian yang penulis lakukan yaitu penulis membuat sistem informasi berbasis web yang dapat diakses oleh masyarakat sehingga masyarakat dapat mengetahui produk yang ada dan melakukan proses pemesanan atau pembayaran secara online.

${ }^{[2]}$ Handoyo (2011) "Sistem Informasi Penjualan Berbasis Web" (Studi Kasus: Toko Benang-benang Hobi Surabaya). Pada penelitian Handoyo (2011) tersebut sama dengan penelitian yang penulis lakukan yaitu dengan tujuan mengubah sistem manual yang sedang berjalan dimana proses pembelian barang oleh pembeli atau konsumen berlangsung dengan cara mendatangi toko tersebut. Sehingga pada penelitian yang dilakukan membuat sebuah sistem informasi penjualan berbasis web yang dimaksudkan untuk mempromosikan produk. Sedangkan perbedaannya terletak pada objek yang diteliti yaitu penulis meneliti pada toko jilbab RJS Kabupaten Sumbawa.

\section{Pengertian Sistem}

Definisi sistem menurut Al Fatta (2007: 6) dan Sutabri (2012: 6).Secara umum keduanya mengemukakan bahwa definisi dari sistem itu hampir serupa.

${ }^{[3]} \mathrm{Al}$ Fatta (2007: 6) mendefinisikan sistem adalah suatu jaringan kerja dari prosedurprosedur yang saling berhubungan atau berkumpul bersama-sama untuk melakukan suatu kegiatan atau untuk melakukan sasaran tertentu. 
${ }^{[4]}$ Sutabri (2012: 6) mendefinisikan sistem adalah sekelompok unsur yang erat hubungannya satu dengan yang yang lain, yang berfungsi bersamasama untuk mencapai tujuan tertentu. Berdasarkan pendapat para ahli diatas penulis dapat menarik kesimpulan bahwa sistem merupakan suatu kumpulan elemen dari sub-sub sistem, komponen, atau unsur-unsur yang terpadu, yang saling berintraksi dan saling berhubungan satu sama lain untuk mencapai suatu tujuan.

\section{Pengertian Informasi}

Adapun definisi dari informasi oleh Hutahean (2015: 10) dan Mulyani (2016: 45). Secara garis besar dikemukakan bahwa definisi dari sistem informasi itu hampir serupa. ${ }^{[5]}$ Hutahean (2015: 10) mendefinisikan bahwa informasi adalah data yang diolah sedemikian rupa menjadi bentuk yang lebih berguna dan lebih berarti bagi penggunanya.

Sedangkan menurut ${ }^{[6]}$ Mulyani (2016: 45) informasi merupakan suatu data yang telah diolah sedemikian rupa menjadi sebuah bentuk yang berarti bagi penerimanya dan bermanfaat dalam proses pengambilan keputusan saat ini atau dimasa yang akan datang.

Dari pengertian diatas dapat ditarik kesimpulan bahwa informasi adalah suatu data yang sudah diolah, dibentuk, atau dimanipulasi sedemikian rupa sesuai dengan keperluan tertentu.

\section{Pengertian Penjualan}

Pada bagian ini, penulis menjabarkan definisi penjualan menurut Rangkuti (2009: 20) dan Riandy (2011: 2).Secara umum keduanya mengemukakan bahwa definisi dari penjualan itu tidak jauh berbeda.

${ }^{[7]}$ Rangkuti (2009: 20) mendefinisikan bahwa penjualan adalah pemindahan hak milik atas barang atau pemberian jasa yang dilakukan penjualan kepada pembeli dengan harga disepakati bersama dengan jumlah yang dibebankan kepada pelanggan dalam penjualan barang dan jasa dalam suatu periode akuntansi.

${ }^{[8]}$ Riandy (2011: 2) mengemukakan penjualan adalah suatu usaha yang terpadu yang bertujuan untuk mengembangkan rencana-rencana yang diarahkan untuk pemuasan dan kebutuhan serta keinginan pembeli yang menghasilkan laba penjualan.

Berdasarkan pendapat para ahli diatas penulis menarik kesimpulan bahwa penjualan merupakan sebuah proses menawarkan barang, produk, maupun jasa kepada konsumen dengan cara merayu atau mempengaruhi konsumen tersebut.

\section{METODE PENELITIAN}

Penelitian ini termasuk penelitian kualitatif yang bersifat deskriptif. Menurut Moleong dalam ${ }^{[9]}$ Arikunto (2016) penelitian kualitatif yaitu tampilan yang berupa kata-kata lisan yang kemudian dicermati oleh peneliti, serta bendabenda yang diamati sampai dengan selesai agar dapat ditarik makna yang tersirat dalam dokumen atau berkas.

Selanjutnya bersifat deskriptif karena dalam pemecahan masalah yang di selidiki yaitu dengan menggambarkan keadaan subjek maupun objek yang diteliti pada saat sekarang berdasarkan faktafakta yang tampak sebagaimana adanya ${ }^{[10]}$ (Sugiyono, 2005). Adapun metode pengumpulan data yang digunakan yaitu observasi, wawancara, dokumentasi, dan studi pustaka.Serta metode pengembangan perangkat lunak yang digunakan yaitu metode waterfall dan menggunakan perancangan terstruktur.

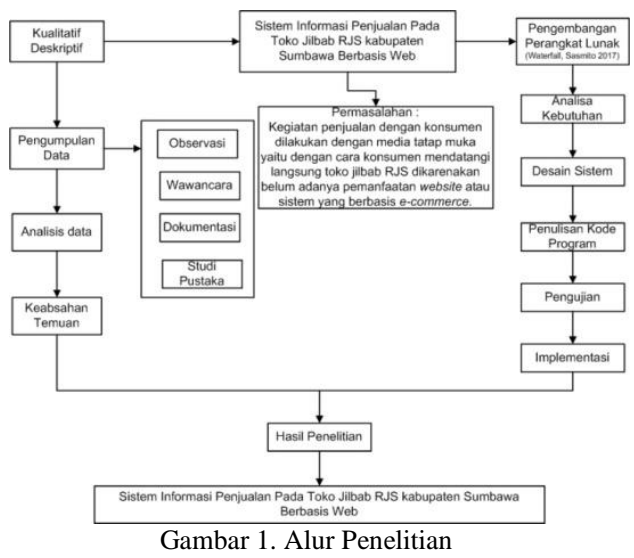

\section{Metode Pengumpulan Data}

Pada tahapan ini dilakukan pengumpulan data dengan menggunakan konsep deskriptif dan data kualitatif. Adapun langkah-langkah yang dilakukan adalah dengan menggunakan empat metode yaitu metode observasi, wawancara, dokumentasi, dan studi pustaka.

a. Observasi

Pada metode ini penulis melakukan pengamatan secara langsung pada toko jilbab RJS Kabupaten Sumbawa guna mengidentifikasi objek atau mengamati proses sistem yang sedang berjalan serta mengetahui data apa saja yang dibutuhkan oleh sistem yang akan dibangun.

b. Wawancara

Pada tahapan ini penulis melakukan wawancara secara langsung kepada pemilik atau pimpinan toko jilbab RJS Kabupaten 
Sumbawa dengan mengajukan beberapa pertanyaan untuk mendapatkan informasi yang lebih jelas.

c. Dokumentasi

Pada tahap ini adalah tahap dokumentasi dimana penulis mengambil data berupa gambar atau foto dari barang atau produk yang disediakan atau dijual pada toko tersebut.

\section{d. Studi Pustaka}

Pada tahap ini penulis mempelajari konsep, teknik, maupun informasi yang dibutuhkan dengan cara mengumpulkan atau mencari dari berbagai sumber seperti internet, buku, jurnal, ataupun artikel ilmiah lainnya yang berkaitan dengan sistem informasi yang akan dibangun.

\section{Metode Pengembangan Perangkat Lunak}

Adapun metode pengembangan perangkat lunak yang digunakan yaitu metode waterfall menurut Sasmito dalam ${ }^{[11]}$ Kandidat (2017) sebagai berikut :

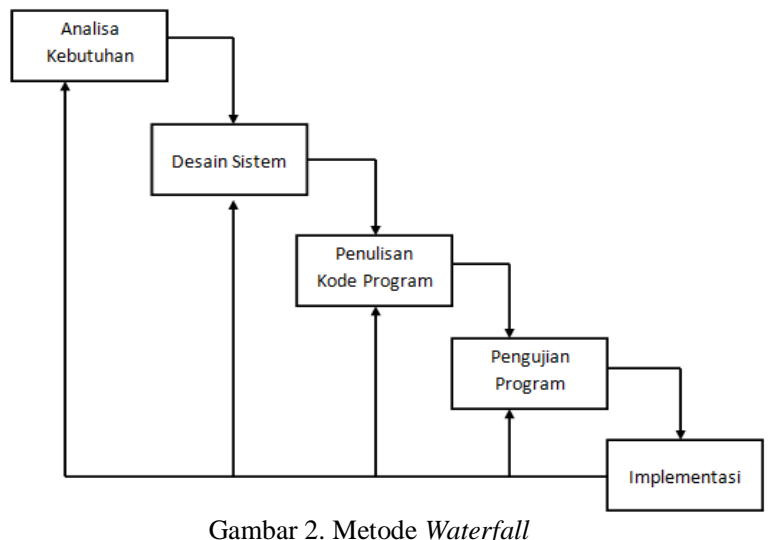

Adapun penjelasan dari tahapan-tahapan pada gambar metode waterfall diatas sebagai berikut:

a. Analisa Kebutuhan

Tahap awal yang dilakukan oleh penulis dalam mengembangkan sistem yang sedang berjalan. Selain menganalisa sistem yang sedang berjalan penulis juga menganalisa kebutuhan perangkat keras, perangkat lunak, kebutuhan pengguna serta kebutuhan data yang akan digunakan.

b. Desain Sistem

Setelah melewati tahap analisa kebutuhan selanjutnya masuk pada tahap desain sistem yaitu dimana penulis akan melakukan perancangan alur aplikasi atau sistem yang akan dibangun. c. Penulisan Kode Program

Pada tahap ini merupakan proses pembuatan aplikasi atau sistem yang sesuai dengan apa yang telah dilakukan pada tahap perencanaan, analisa dan desain sistem. Yang kemudian dilakukan penulisan kode program.

d. Pengujian Program

Tahap ini merupakan tahap pengujian dan tahap pendukung yang artinya aplikasi atau sistem yang telah dibuat atau dibangun dari hasil analisis masalah yang telah melalui tahapan analisa, desain sistem, penulisan kode program barulah kemudian masuk kedalam proses pengujian program, sehingga akan dapat diketahui seperti apa hasil kerja dari aplikasi tersebut, kemudian akan diketahui pula apakah aplikasi yang telah dibuat berjalan baik sesuai dengan apa yang diharapkan.

e. Implementasi

Pada tahap ini dilakukan proses penerapan sistem informasi yang telah selesai di buat pada tempat penelitian untuk mengganti sistem yang sebelumnya.

\section{HASIL DAN PEMBAHASAN}

\section{Perancangan Sistem}

Perancangan Sistem Informasi Penjualan Pada Toko Jilbab RJS Kabupaten Sumbawa meliputi:

a. Sistem Berjalan

Berdasarkan hasil wawancara yang telah dilakukan pada Toko Jilbab RJS Kabupaten Sumbawa diketahui sistem yang sedang berjalan pada saat ini memiliki alur seperti yang terlihat pada gambar berikut: 


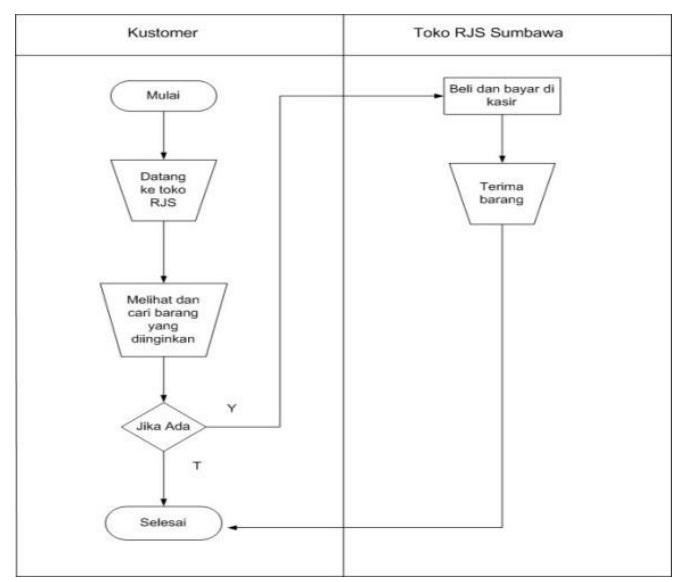

Gambar 3. Sistem Berjalan

b. Sistem Usulan

Berdasarkan alur sistem yang berjalan sebelumnya, peneliti bermaksud mengusulkan pembuatan sistem informasi yang dapat memudahkan kustomer dalam mengetahui barang atau produk yang tersedia pada toko jilbab RJS Kabupaten Sumbawa. Adapun alur sistem yang diusulkan pada penelitian ini yaitu dapat dilihat pada gambar berikut:

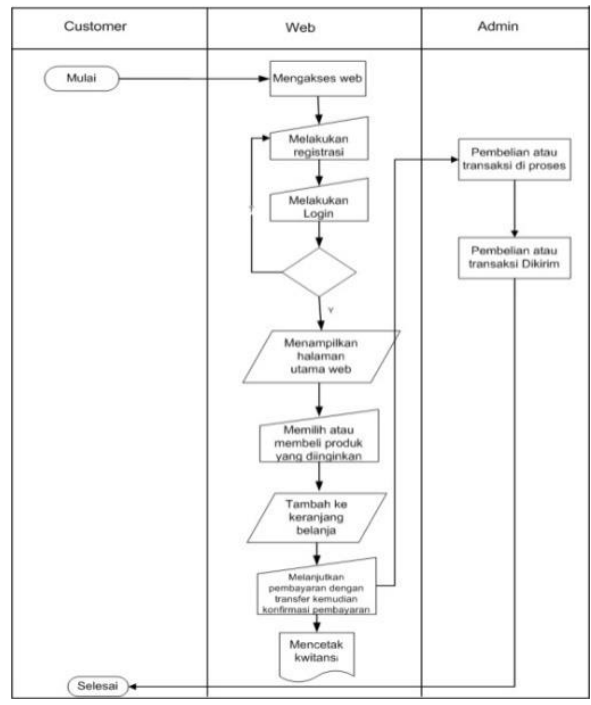

Gambar 4.Sistem usulan

\section{Rancangan Data Flow Diagram}

Pada rancangan data flow diagram pada penelitian ini terdiri dari diagram konteks, data flow diagram level zero, data flow diagram level 1. a. Diagram konteks

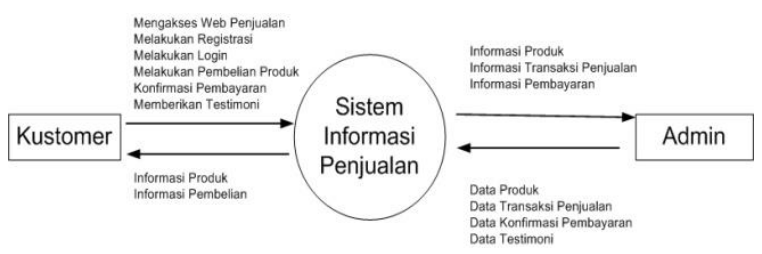

Gambar 5. Diagram Konteks

b. Data Flow Diagram Level Zero

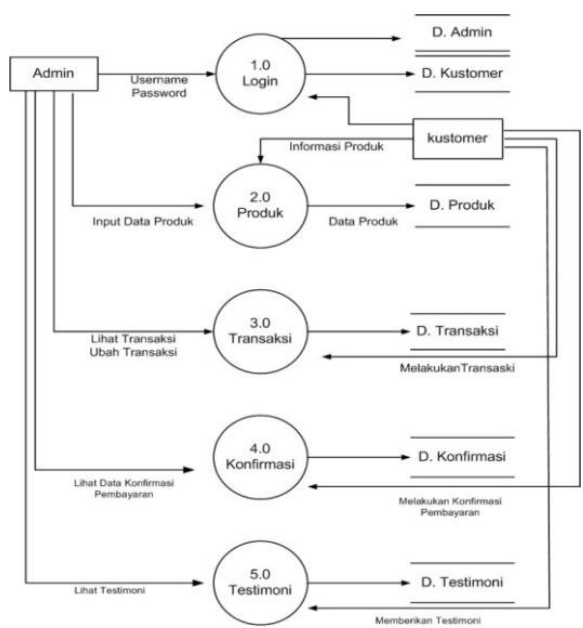

Gambar 6. DFD Level 0

c. Data Flow Diagram Level 1 Proses 1.0

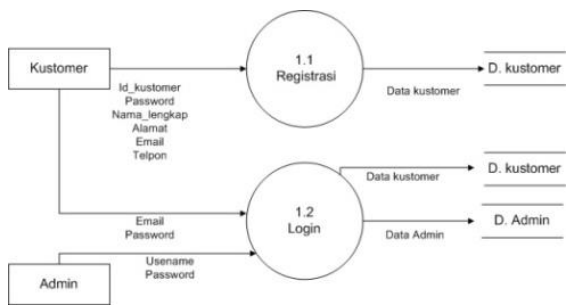

Gambar 7. DFD Level 1 Proses 1.

d. Data Flow Diagram Level 1 Proses 2.0

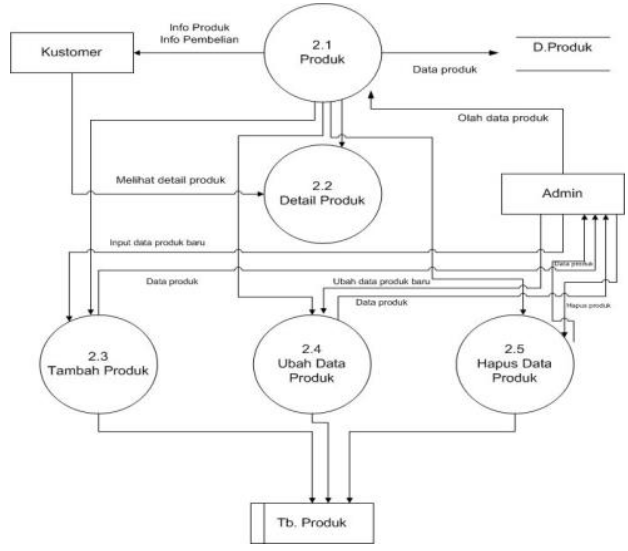

Gambar 8. DFD Level 1 Proses 2.0 


\section{Entity Relationship Diagram}

Berikut adalah gambar dari entity relationship diagram:

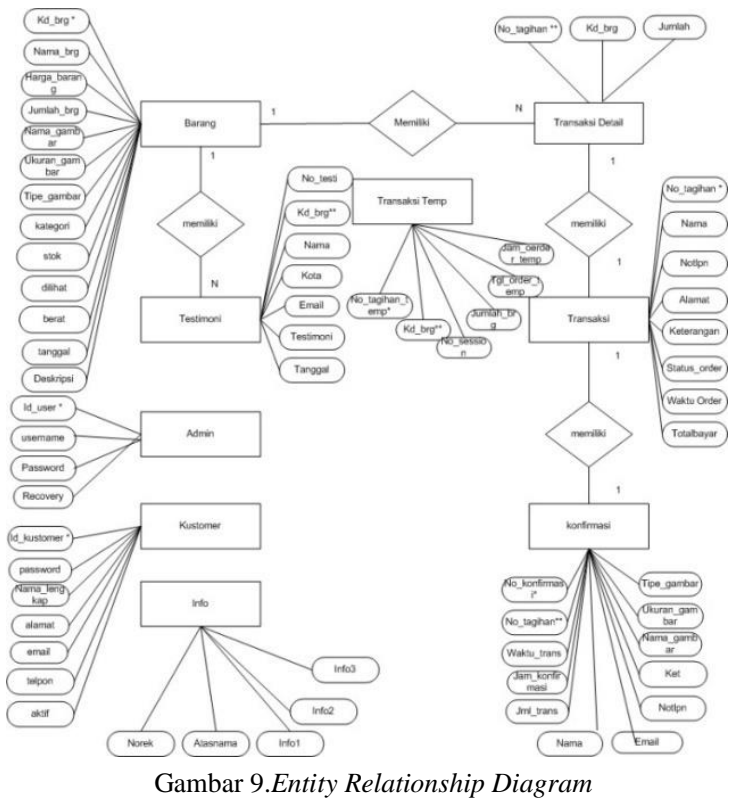

\section{Implementasi Program}

Berikut hasil implementasi dari Sistem Informasi Penjualan pada toko jilbab RJS Kabupaten Sumbawa :

a. Tampilan halaman login

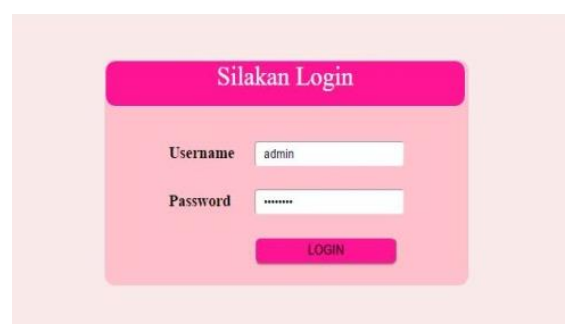

Gambar 10. Halaman login

b. Tampilan halaman menu utama

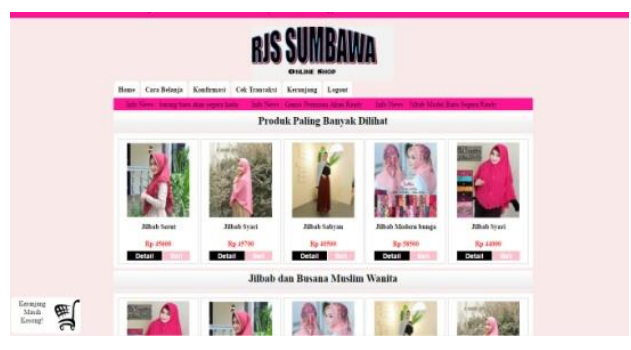

Gambar 11. Halaman menu utama c. Tampilan halaman keranjang belanja

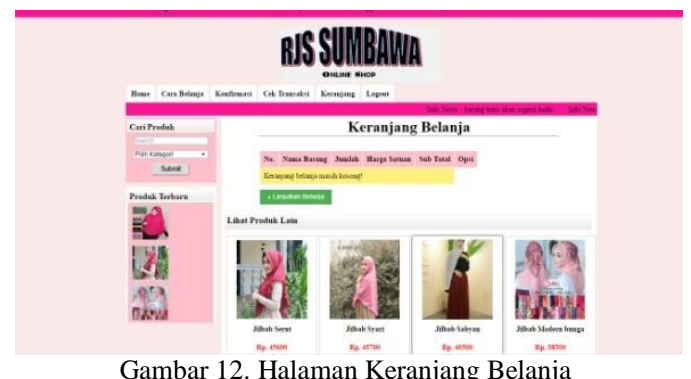

\section{Pengujian Sistem}

Dalam pengujian ini dilakukan dengan metode black box yaitu pengecekan input dan output untuk menentukan apakah keluaran sudah sesuai dengan yang diharapkan. Adapun proses pengujian sistem informasi ini adalah sebagai berikut:

Tabel 1. Pengujian Program

\begin{tabular}{|c|c|c|c|c|}
\hline No & $\begin{array}{c}\text { Pengujia } \\
n\end{array}$ & Tujuan & Indikator & $\begin{array}{c}\text { Hasil } \\
\text { Penguji } \\
\text { an }\end{array}$ \\
\hline 1 & \begin{tabular}{|l|} 
Pengujian \\
Login
\end{tabular} & $\begin{array}{l}\text { Mengecek } \\
\text { proses menu } \\
\text { login }\end{array}$ & $\begin{array}{l}\text { Masuk ke } \\
\text { halaman } \\
\text { dashboard }\end{array}$ & Berhasil \\
\hline 2 & $\begin{array}{l}\text { Pengujian } \\
\text { halaman } \\
\text { tambah } \\
\text { barang }\end{array}$ & $\begin{array}{l}\text { Mengecek } \\
\text { pengoperasia } \\
\text { n dengan } \\
\text { melakukan } \\
\text { inputan atau } \\
\text { penambahan } \\
\text { barang }\end{array}$ & $\begin{array}{l}\text { Inputan } \\
\text { dilakukan } \\
\text { oleh admin. } \\
\text { Jika } \\
\text { berhasil } \\
\text { maka } \\
\text { tersimpan } \\
\text { dan tampil } \\
\text { pada tabel } \\
\text { daftar } \\
\text { barang. } \\
\text { Jika salah } \\
\text { maka tidak } \\
\text { akan } \\
\text { menampilk } \\
\text { an daftar } \\
\text { barang. }\end{array}$ & Berhasil \\
\hline 3 & $\begin{array}{l}\text { Edit } \\
\text { barang }\end{array}$ & $\begin{array}{l}\text { Mengecek } \\
\text { apakah } \\
\text { barang dapat } \\
\text { diedit. }\end{array}$ & $\begin{array}{l}\text { Jika barang } \\
\text { berhasil } \\
\text { diedit maka } \\
\text { barang } \\
\text { akan } \\
\text { tersimpan } \\
\text { dan } \\
\text { berubah } \\
\text { dari } \\
\text { sebelumnya } \\
\text { sesuai } \\
\text { dengan } \\
\text { yang telah } \\
\text { diedit. }\end{array}$ & Berhasil \\
\hline 4 & Hapus & Mengecek & Menampilk & Berhasil \\
\hline
\end{tabular}




\begin{tabular}{|c|c|c|c|c|}
\hline & barang & $\begin{array}{l}\text { apakah data } \\
\text { barang dapat } \\
\text { terhapus }\end{array}$ & $\begin{array}{l}\text { an warning } \\
\text { apakah data } \\
\text { benar-benar } \\
\text { akan } \\
\text { dihapus, } \\
\text { jika telah } \\
\text { dihapus } \\
\text { maka data } \\
\text { akan } \\
\text { terhapus } \\
\text { dari daftar } \\
\text { tabel. }\end{array}$ & \\
\hline 5 & $\begin{array}{l}\text { Pengujian } \\
\text { daftar } \\
\text { barang } \\
\text { atau } \\
\text { produk }\end{array}$ & $\begin{array}{l}\text { Mengecek } \\
\text { apakah data } \\
\text { barang yang } \\
\text { telah } \\
\text { diinputkan } \\
\text { masuk atau } \\
\text { tersimpan } \\
\text { dalam daftar } \\
\text { produk }\end{array}$ & $\begin{array}{l}\text { Melihat } \\
\text { daftar } \\
\text { produk } \\
\text { serta dapat } \\
\text { melakukan } \\
\text { proses edit } \\
\text { dan hapus } \\
\text { data produk }\end{array}$ & Berhasil \\
\hline 6 & $\begin{array}{l}\text { Pengujian } \\
\text { keranjang } \\
\text { belanja }\end{array}$ & $\begin{array}{l}\text { Mengecek } \\
\text { apakah } \\
\text { produk yang } \\
\text { dibeli dapat } \\
\text { masuk } \\
\text { kedalam } \\
\text { keranjang } \\
\text { belanja }\end{array}$ & $\begin{array}{l}\text { Inputan } \\
\text { dilakukan } \\
\text { oleh } \\
\text { konsumen }\end{array}$ & Berhasil \\
\hline 7 & \begin{tabular}{|ll}
\multicolumn{2}{|l}{ Pengujian } \\
log $\quad$ out \\
atau \\
keluar
\end{tabular} & $\begin{array}{l}\text { Mengecek } \\
\text { proses keluar } \\
\text { sistem }\end{array}$ & $\begin{array}{ll}\text { Dapat } & \\
\text { keluar } & \text { dari } \\
\text { sistem } & \end{array}$ & Berhasil \\
\hline
\end{tabular}

\section{KESIMPULAN DAN SARAN}

\section{Kesimpulan}

Berdasarkan hasil dari analisis dan perancangan sistem yang telah dilakukan. Adapun kesimpulan yang dapat ditarik oleh penulis dari proses penelitian ini yaitu Sistem Informasi Penjualan pada toko jilbab RJS Kabupaten Sumbawa Berbasis Web telah selesai dirancang atau dibangun dengan menggunakan bahasa pemrograman PHP dan database $M y S Q L$.

Metode perancangan yang digunakan yaitu metode perancangan terstruktur yang meliputi Diagram Konteks, Data Flow Diagram, dan Entity Relationship Diagram. Dan perancangan tampilan alur serta interface menggunakan Microsoft Office Visio 2007 dan Balsamiq Mockup 3. Selanjutnya dari segi admin, dapat mengolah data pada web dengan proses tambah, edit, dan hapus data.

\section{Saran}

Dari hasil pembuatan Sistem Informasi Penjualan pada toko jilbab RJS Kabupaten Sumbawa berbasis $W e b$, adapun saran yang dapat penulis sampaikan baik kepada toko jilbab RJS
Sumbawa maupun untuk pengembangan selanjutnya agar menjadi lebih baik yaitu:

a. Dengan demikian sistem informasi ini dapat menjadi masukan kepada pemilik toko jilbab RJS Sumbawa sebagai salah satu bentuk peningkatan mutu dalam proses perniagaan. Dengan menerapkan sistem yang telah dibangun dimana menghasilkan sistem informasi yang dapat diakses oleh konsumen sehingga konsumen dapat melihat informasi mengenai produk yang tersedia pada toko jilbab RJS Sumbawa serta konsumen dapat melakukan proses transaksi.

b. Kedepannya dapat ditambahkan menu laporan untuk admin. Sehingga admin dapat mengetahui jumlah penjualan maupun stok produk.

c. Diharapkan kedepannya ruang lingkup dari proses pengiriman atau pengantaran barang dapat mencakup wilayah luar selain kota Sumbawa.

\section{Daftar Pustaka}

[1] Prasetyo, Rachman Herry. 2015. Perancangan Sistem Penjualan Berbasis Aplikasi Desktop pada CV. Canangsari Semarang. Jurnal.

[2] Handoyo, Osie Holy. 2011. Sistem Informasi Penjualan Berbasis Web. Skripsi : Universitas Sanata Dharma.

[3] Al-Fatta, Hanif. 2007. Analisis dan Perancangan Sistem Informasi. Yogyakarta: Penerbit Andi.

[4] Sutabri, Tata. 2012. Analisis Sistem Informasi. Yogyakarta: CV Andi Offset.

[5] Hutahean, Japerson. 2015. Konsep Sistem Informasi. Yogyakarta: CV Budi Utama.

[6] Mulyani, Sri. 2016 Metode Analisis dan Perancangan Sistem.Bandung: Abdi Sistematika.

[7] Rangkuti, Freddy. 2009. Strategi Promosi yang Kreatif \& Analisis Kasus Integrated Marketing Communication. Jakarta: PT. Gramedia Pustaka Utama.

[8] Riandy, Huliyah dan Subiyakto. 2011. Rancang Bangun Sistem Informasi Penjualan Barang. Jurnal Sistem Informasi, Vol.1.No.,16.

[9] Arikunto, Suharsimi. 2016. Prosedur Penelitian. Penerbit: Rineka Cipta.

[10] Sugiyono. 2005. Memahami Penelitian Kualitatif. Bandung : ALFABET.

[11] Kandidat, Aji. 2018. "Rancang Bangun Sistem Informasi Perizinan Pengeluaran Ternak". Skripsi. Sumbawa: Universitas Teknologi Sumbawa. 